\title{
REGIONALIZAÇÃO DE VAZÕES COM BASE EM MODELO DIGITAL DE ELEVAÇÃO PARA A BACIA DO RIO PARAÍBA DO SUL
}

\author{
LUIZ G. N. BAENA ${ }^{1}$, DEMETRIUS D. DA SILVA², FERNANDO F. PRUSKI ${ }^{2}$, \\ MARIA L. CALIJURI ${ }^{3}$
}

\begin{abstract}
RESUMO: A regionalização de vazões tem sido realizada com o objetivo de disponibilizar informações hidrológicas em locais sem dados ou com poucas informações disponíveis, porém a determinação das características físicas das bacias de drenagem para cada local de interesse limita consideravelmente a aplicação dos resultados de um estudo convencional de regionalização de vazões. Uma das soluções para esse problema é a automação do processo de delimitação de bacias, utilizandose de modelo digital de elevação hidrologicamente consistente (MDEHC). O objetivo principal deste trabalho foi a regionalização de vazões máxima, mínima e média de longo período e da curva de permanência para a bacia hidrográfica do Rio Paraíba do Sul, a montante da cidade de Volta Redonda, com base em um MDEHC. O modelo digital de elevação mostrou-se hidrologicamente consistente, possibilitando, assim, a determinação automática das características físicas da bacia. Foram identificadas quatro regiões hidrologicamente homogêneas e obtidas equações de regressão em que a área de drenagem e o comprimento do curso d'água principal se caracterizaram como as variáveis mais expressivas para a representação das diversas variáveis e funções regionalizadas.
\end{abstract}

PALAVRAS-CHAVE: sistema de informações geográficas, bacia hidrográfica, recursos hídricos.

\section{REGIONALIZATION OF THE STREAM-FLOW USING A DIGITAL ELEVATION MODEL FOR THE SOUTH PARAÍBA WATERSHED}

SUMMARY: The stream-flow regionalization is made in locations where the hydrologic information is not available, however the determination of the physical characteristics to each place of interest considerably limits the application of the results of a conventional study of the stream-flow regionalization. One of the solutions for this problem is the automation of the process using a hidrologically consistent digital elevation model (HCDEM). The main objective of this paper was the regionalization of the mean, maximum and minimum stream-flow in South Paraíba River using a HCDEM. The duration curve also was regionalized. The digital elevation model was shown hidrologically consistent making possible the automation of the process to estimate the physical characteristics. Four hidrologically homogeneous areas were identified for this studied area and the regression equations were obtained. The drainage area and the length of the main river were the most important variables to represent the regionalysed functions.

KEYWORDS: geographic information systems, watershed, water resources.

\footnotetext{
${ }^{1}$ Doutorando em Engenharia Agrícola, Universidade Federal de Viçosa, UFV, Viçosa - MG, Fone: (0XX31) 3891.3672 -3899.2735, email: lbaena@ufv.br. Bolsista CNPq.

${ }^{2}$ Prof. Dr., Departamento de Engenharia Agrícola, Universidade Federal de Viçosa, UFV, Viçosa - MG, Fone: (0XX31) 3899.2729, email: david@ufv.bre ffpruski@ufv.br. Bolsista CNPq.

${ }^{3}$ Prof. Dr., Departamento de Engenharia Civil, Universidade Federal de Viçosa, UFV, Viçosa - MG, Fone: (0XX31) 3899.3098, e-mail: calijuri@ufv.br.

Recebido pelo Conselho Editorial em: 20-10-2003
}

Aprovado pelo Conselho Editorial em: 19-7-2004 


\section{INTRODUÇÃO}

Uma rede hidrométrica dificilmente cobre todos os locais de interesse necessários ao gerenciamento dos recursos hídricos de uma região. Sempre existirão lacunas temporais e espaciais que deverão ser preenchidas com base em metodologias apropriadas.

Para suprir a deficiência da rede hidrométrica no Brasil, uma técnica que tem sido utilizada com resultados satisfatórios, é a regionalização hidrológica (ELETROBRÁS, 1985). De acordo com FILL (1987), em sentido amplo, entende-se por regionalização hidrológica qualquer processo de transferência de informações das estações hidrométricas para outros locais sem observações.

Nos estudos de regionalização, devem ser consideradas as características físicas e climáticas das bacias que mais interferem na distribuição espacial da vazão e que sejam facilmente mensuráveis. A determinação dessas variáveis para cada local de interesse limita consideravelmente a obtenção e a aplicação dos resultados de um estudo convencional de regionalização de vazões, pois se trata de um processo mecânico e trabalhoso (BAENA, 2002).

Nas últimas duas décadas, diversos algoritmos têm sido implementados em módulos específicos dos sistemas de informações geográficas com a finalidade de automatizar a extração de características morfométricas da superfície terrestre, a partir dos modelos digitais de elevação. As vantagens da automação em relação aos procedimentos manuais são a maior eficiência e confiabilidade dos dados digitais obtidos (CHAVES, 2002).

A eficiência da extração das características físicas, medida em termos de precisão e de exatidão, está diretamente relacionada com a qualidade do modelo digital de elevação e do algoritmo utilizado. O modelo digital de elevação deve representar o relevo de forma fidedigna e assegurar a convergência do escoamento superficial para a rede de drenagem mapeada, garantindo, assim, a sua consistência hidrológica. Tem-se, portanto, a necessidade de utilizar um modelo digital de elevação hidrologicamente consistente (MDEHC).

Tendo em vista a necessidade de regionalização de variáveis hidrológicas e de automatização do processo de determinação das variáveis explicativas usadas nas equações regionalizadas, desenvolveuse o presente trabalho, que teve por objetivos obter um modelo digital de elevação hidrologicamente consistente para a bacia hidrográfica do Rio Paraíba do Sul, a montante da cidade de Volta Redonda, e proceder à regionalização de vazões máxima, mínima e média de longo período e da curva de permanência para a bacia em estudo.

\section{MATERIAL E MÉTODOS}

A bacia hidrográfica do Rio Paraíba do Sul abrange parte dos Estados de Minas Gerais, Rio de Janeiro e São Paulo, com área de drenagem de aproximadamente $57.000 \mathrm{~km}^{2}$. O estudo foi realizado no trecho da bacia entre os paralelos $22^{\circ} 34^{\prime}$ e $23^{\circ} 28^{\prime}$ e os meridianos $44^{\circ} 10^{\prime}$ e $46^{\circ} 15^{\prime}$, até as proximidades da cidade de Volta Redonda - RJ.

Essa bacia foi selecionada para o estudo por possuir boa densidade de estações fluviométricas e por se encontrar numa região estratégica e bem desenvolvida, com intensivo uso da água. Além disso, toda a bacia possui cobertura das cartas topográficas na escala utilizada, que foi de 1:50.000.

\section{Obtenção do MDEHC}

Foram confeccionados 45 mapas digitais a partir da base de dados do IBGE e do Ministério do Exército na escala 1:50.000. Foram digitalizadas a hidrografia e as curvas de nível. As curvas de nível, devido à presença de inconsistências decorrentes do processo de aquisição em mesa digitalizadora, foram visualmente ajustadas à hidrografia orientada. Já a hidrografia foi processada e verificada de forma que se obtivesse a orientação de todas as feições para o sentido do escoamento. O modelo digital 
de elevação (MDE), com resolução de 30 x 30 m, foi gerado a partir da interpolação das curvas de nível digitalizadas, utilizando-se do módulo TOPOGRID, disponível no software ARC/INFO.

As depressões espúrias (células cercadas por outras com maiores valores de elevação) remanescentes foram removidas, garantindo-se a consistência do escoamento superficial ao longo da rede de drenagem gerada pelo modelo. Buscou-se, também, garantir a coincidência espacial da drenagem gerada pelo modelo com a drenagem vetorial digitalizada das bases cartográficas. A coincidência espacial dessas duas feições é um parâmetro qualitativo de verificação da consistência hidrológica do modelo, pelo menos no que diz respeito à representação espacial da drenagem. Outra forma de verificação adotada foi a consistência da delimitação automática de bacias hidrográficas de contribuição, a montante de pontos escolhidos de forma aleatória. Nesse caso, verificou-se a existência de erros, como cortes na hidrografia e localização inconsistente de divisores de água. Esses foram os dois métodos utilizados para a avaliação do MDEHC gerado.

\section{Seleção e análise dos dados básicos}

Para a realização do estudo, foram utilizados dados fluviométricos e pluviométricos pertencentes às redes da Agência Nacional de Águas (ANA), Departamento de Águas e Energia Elétrica do Estado de São Paulo (DAEE-SP) e Light Serviços de Eletricidade S.A. (LIGHT). Após a obtenção dos dados, elaborou-se um diagrama de barras para as estações fluviométricas e pluviométricas.

De posse do diagrama de barras e do mapa de localização das estações fluviométricas procedeuse à análise das estações quanto ao período de operação e localização geográfica, visando à identificação do período-base (período comum de observações) a ser usado na regionalização. Foi selecionado preliminarmente, para o presente estudo, o período de 1970 a 1997, porém, analisando-se a existência e influência dos reservatórios localizados na área em estudo, optou-se por utilizar o período-base de 1978 a 1997, já que o último reservatório a entrar em operação na área foi o Paraibuna/Paraitinga, construído no Rio Paraibuna e com início de operação no ano de 1978. Estações fluviométricas que apresentavam menos de oito anos de dados dentro do período-base selecionado (1978-1997) foram excluídas da análise e, em função disso, foram efetivamente selecionadas para o uso no estudo de regionalização 30 estações fluviométricas (Figura 1). Os dados fluviométricos de cada uma dessas estações selecionadas foram analisados quanto à continuidade entre as vazões de cada estação com as estações localizadas a montante e à jusante.

O período-base adotado para os dados pluviométricos foi o mesmo dos dados fluviométricos, ou seja, 1978 a 1997, tendo sido selecionadas 37 estações pluviométricas para o estudo de regionalização.

Após a análise dos dados hidrológicos, àqueles inexistentes ou considerados inconsistentes foram atribuídas falhas para posterior preenchimento. O preenchimento de falhas, tanto dos dados de vazão quanto de precipitação, foi realizado por meio de correlações segundo critérios consagrados de escolha de bases para as regressões. 


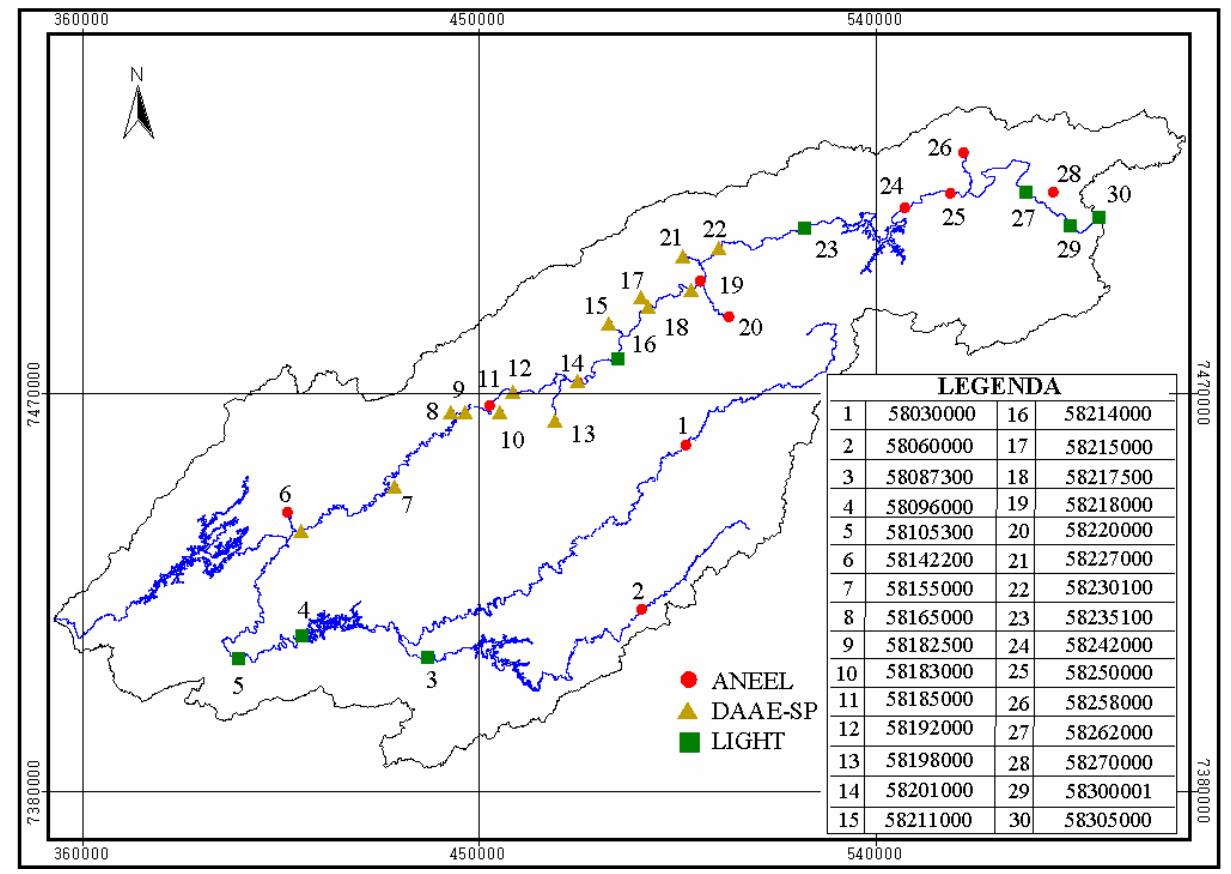

FIGURA 1. Mapa com as estações fluviométricas usadas na regionalização.

\section{Obtenção das características físicas e de precipitação}

As características físicas utilizadas na regionalização foram a área de drenagem (A), o comprimento do rio principal (L), a densidade de drenagem $(\mathrm{Dd})$, a declividade média da bacia $\left(\mathrm{S}_{\mathrm{m}}\right)$ e a declividade média do rio principal $\left(\mathrm{S}_{\mathrm{rp}}\right)$. Foram também utilizadas diversas características de precipitação média: total anual com base nos anos hidrológico $\left(\mathrm{P}_{\mathrm{aH}}\right)$ e civil $\left(\mathrm{P}_{\mathrm{aC}}\right)$, semestre mais chuvoso $\left(\mathrm{P}_{\mathrm{sc}}\right)$ e trimestre mais chuvoso $\left(\mathrm{P}_{\mathrm{tc}}\right)$, semestre mais $\operatorname{seco}\left(\mathrm{P}_{\mathrm{ss}}\right)$ e trimestre mais seco $\left(\mathrm{P}_{\mathrm{ts}}\right)$, mês mais chuvoso $\left(\mathrm{P}_{\mathrm{mc}}\right)$ e máxima diária anual $\left(\mathrm{P}_{\mathrm{máx}}\right)$.

A delimitação das bacias de drenagem de cada estação fluviométrica foi feita de modo automático, com base no MDEHC obtido, bastando para tal a localização exata de cada estação.

De posse da delimitação da área de cada bacia, passou-se então à determinação das diferentes características físicas usadas no estudo de regionalização. $\mathrm{O}$ cálculo da densidade de drenagem $\left(\mathrm{D}_{\mathrm{d}}\right)$ foi realizado a partir da estimativa de variáveis primárias, como a área da bacia (A) e o comprimento total dos cursos d'água $\left(\mathrm{L}_{\text {total }}\right)$. Os cursos d'água principais ( $\mathrm{L}$ ) foram identificados como aqueles que drenavam a maior área em suas respectivas bacias. Já as determinações da declividade média da bacia $\left(S_{\mathrm{m}}\right)$ e da declividade do curso d'água principal $\left(\mathrm{S}_{\mathrm{rp}}\right)$ foram feitas com o auxílio do modelo digital de elevação hidrologicamente consistente (MDEHC).

Para o cálculo da precipitação média sobre a bacia, que se refere à área de drenagem de cada uma das estações fluviométricas, foi utilizado o método do Polígono de Thiessen.

\section{Identificação das regiões homogêneas}

Foram utilizados dois critérios para a identificação das regiões homogêneas, conforme ELETROBRÁS (1985):

a) Critério baseado na análise da distribuição de freqüência das vazões adimensionalizadas de cada estação: o princípio em que se baseia esse critério é que as distribuições de frequiência das vazões médias, máximas e mínimas das estações localizadas em uma região hidrologicamente homogênea seguem uma mesma tendência, sendo as diferenças proporcionais à média das séries de vazões 
consideradas. Essa característica permite que, ao se obterem séries transformadas de vazões, por meio da divisão dos seus valores pelas respectivas médias, as distribuições de freqüência dessas séries transformadas sejam idênticas.

b) Critério estatístico baseado na análise do ajuste de modelo de regressão múltipla: nesse critério, são estabelecidas regressões múltiplas entre as séries de vazões (média, máxima e mínima) e as diferentes características físicas e climáticas das bacias. As regiões hidrologicamente homogêneas são definidas em função da distribuição geográfica das estações e da combinação de estações que apresenta o melhor ajuste, avaliado por intermédio do teste estatístico da função $\mathrm{F}$, do coeficiente de determinação ajustado, do desvio-padrão dos erros do ajustamento e dos erros porcentuais (\%dr) entre os valores das vazões observadas e estimadas pelos modelos de regressão obtidos para cada uma das regiões homogêneas.

Quando os dois critérios apresentaram bons resultados, ou seja, quando as estações de uma mesma região apresentaram valores do coeficiente de regressão "b" próximos (critério 1) e quando os valores do teste estatístico da função $\mathrm{F}$, do coeficiente de determinação ajustado, do desvio-padrão dos erros do ajustamento e dos erros porcentuais (\%dr) entre os valores das vazões observadas e estimadas pelos modelos de regressão obtidos para cada uma das regiões homogêneas foram aceitáveis (critério 2), a região foi definida como hidrologicamente homogênea para as vazões estudadas; entretanto, nos casos em que isso não ocorreu, houve a necessidade de subdividir a região ou reorganizar as estações dentro das regiões e reiniciar o processo.

\section{Regionalização de vazões máxima, mínima e média}

As vazões máximas e mínimas foram regionalizadas com um determinado nível de risco, ou seja, associadas a um período de retorno específico (T). Já a vazão média de longo período, por ser caracterizada como a média das vazões médias diárias anuais, foi regionalizada sem se considerar o nível de risco.

Verificou-se por meio da análise da data de ocorrência dos valores máximos diários anuais que, na quase totalidade dos anos, estes ocorriam entre os meses de setembro e abril sendo, por isso, adotado para a regionalização das vazões máxima e média o ano hidrológico com início em setembro. Tendo em vista o fato de não ter sido identificado de forma clara, ao longo da bacia, o período definido de ocorrência de eventos mínimos, optou-se por trabalhar com o ano civil (janeiro-dezembro) na regionalização da vazão mínima.

O intervalo de tempo utilizado para a definição da vazão média foi de um dia, de modo que foi determinada uma vazão média (baseada em dados diários) de longo período para cada estação fluviométrica estudada.

A regionalização da vazão média foi realizada com base na determinação da curva adimensional de probabilidade de vazões médias anuais e no ajuste da equação de regressão entre a vazão média de longo período e as características físicas e climáticas da bacia.

As séries anuais de vazões máximas diárias e mínimas com sete dias de duração, para cada estação, foram submetidas à análise estatística, para a identificação do modelo probabilístico que melhor se ajustava aos dados. Os modelos de distribuição de eventos máximos ajustados foram os seguintes: Gumbel, Log-Normal a dois e três parâmetros, Pearson e Log-Pearson III. Já para eventos mínimos, foram utilizadas as seguintes distribuições: Log-Normal a dois e três parâmetros, Pearson III, Log-Pearson III e Weibull.

A seleção da distribuição de probabilidade ajustável a cada série histórica foi efetuada utilizando-se do teste de aderência de Kolmogorov-Smirnov e o coeficiente de variação. 
Após a seleção da distribuição probabilística com melhor ajuste aos dados de vazões, foram obtidos os valores das vazões mínimas com sete dias de duração, associadas aos períodos de retorno de 2; 5; 10; 20 e 50 anos, e das vazões máximas para 2; 10; 20; 50 e 100 anos.

De posse dos dados de vazões máxima, mínima e média de longo período e das características físicas $\left(\mathrm{A}, \mathrm{L}, \mathrm{Dd}, \mathrm{S}_{\mathrm{m}}\right.$ e $\left.\mathrm{S}_{\mathrm{rp}}\right)$ e climáticas $\left(\mathrm{P}_{\mathrm{aH}}, \mathrm{P}_{\mathrm{ac}}, \mathrm{P}_{\mathrm{sc}}, \mathrm{P}_{\mathrm{tc}}, \mathrm{P}_{\mathrm{mc}}, \mathrm{P}_{\mathrm{máx}}, \mathrm{P}_{\mathrm{ss}}, \mathrm{P}_{\mathrm{ts}}\right)$ correspondentes às áreas de drenagem das diferentes estações fluviométricas pertencentes a uma mesma região homogênea, foi aplicada a regressão múltipla à vazão média de longo período e às vazões específicas máximas e mínimas para os períodos de retorno estudados.

As características de precipitação média utilizadas para a regionalização da vazão máxima foram $\mathrm{P}_{\mathrm{mc}}, \mathrm{P}_{\mathrm{tc}}, \mathrm{P}_{\mathrm{sc}}$ e $\mathrm{P}_{\text {máx }}$ e para a regionalização da vazão mínima $\mathrm{P}_{\mathrm{ts}}, \mathrm{P}_{\mathrm{ss}}$ e $\mathrm{P}_{\mathrm{aC}}$. Na regionalização da vazão média, foi utilizada apenas $\mathrm{P}_{\mathrm{aH}}$.

Os melhores modelos resultantes da aplicação da regressão múltipla foram selecionados observando-se: maiores valores do coeficiente de determinação ajustado, menores valores de erropadrão fatorial, resultados significativos pelo teste $\mathrm{F}$ e menor número de variáveis independentes.

\section{Regionalização da curva de permanência}

A metodologia utilizada na regionalização da curva de permanência compreendeu as seguintes etapas:

- determinação da curva de permanência de cada posto fluviométrico;

- determinação das vazões associadas a 50; 75; 80; 90 e 95\% de permanência no tempo, a partir da curva de permanência obtida para cada estação, e

- estabelecimento das equações de regressão para $\mathrm{Q}_{50}, \mathrm{Q}_{75}, \mathrm{Q}_{80}, \mathrm{Q}_{90}$ e $\mathrm{Q}_{95}$ com base nas características físicas (A, Dd, L, $\mathrm{S}_{\mathrm{m}}$ e $\left.\mathrm{S}_{\mathrm{rp}}\right)$ e climáticas $\left(\mathrm{P}_{\mathrm{aC}}, \mathrm{P}_{\mathrm{ss}}\right.$ e $\left.\mathrm{P}_{\mathrm{ts}}\right)$ da bacia de drenagem, para cada região homogênea.

\section{RESULTADOS E DISCUSSÃO}

O modelo digital de elevação mostrou-se hidrologicamente consistente, devido ao fato de a rede de drenagem gerada ter apresentado sobreposição com a rede de drenagem mapeada (Figura 2a) e de a delimitação automática das áreas de drenagem ter apresentado qualidade satisfatória (Figura 2b).

As características físicas da área representativa de cada estação fluviométrica utilizada puderam ser fácil e precisamente determinadas com a utilização do MDEHC gerado (Figura 3). A área de drenagem variou de valores desde $30,46 \mathrm{~km}^{2}$ até $15.839,24 \mathrm{~km}^{2}$. A densidade de drenagem variou de 1,96 a 3,43 $\mathrm{km} \mathrm{km}^{-2}$ e o comprimento do rio principal de 15,08 a 898,31 km para as áreas de drenagem correspondentes às diferentes estações fluviométricas. Esses valores são altamente influenciáveis pela escala dos mapas utilizados para a geração do MDEHC, que, no presente trabalho, foi de 1:50.000. Diversos pesquisadores (SILVA, 2002a; BAENA, 2002 e EUCLYDES, 2002), trabalhando com mapas na escala de 1:250.000, obtiveram valores de densidade de drenagem variando de 0,17 a $0,88 \mathrm{~km} \mathrm{~km}^{-2}$.

Os valores de declividade média das áreas de drenagem das diferentes estações fluviométricas variaram de 7,2 até $40,2 \%$, sendo a declividade média da área em estudo em torno de $16 \%$, e a declividade média dos cursos d'água principais variou de 0,04 até 2,3\%.

Na obtenção das características de precipitação média pluvial na região em estudo, verificou-se que o mês mais chuvoso normalmente é dezembro, o mais seco julho, o trimestre mais chuvoso inclui os meses de novembro, dezembro e janeiro, enquanto o mais seco inclui junho, julho e agosto. Já a precipitação máxima diária ocorre, na maior parte dos anos, no mês de janeiro. 


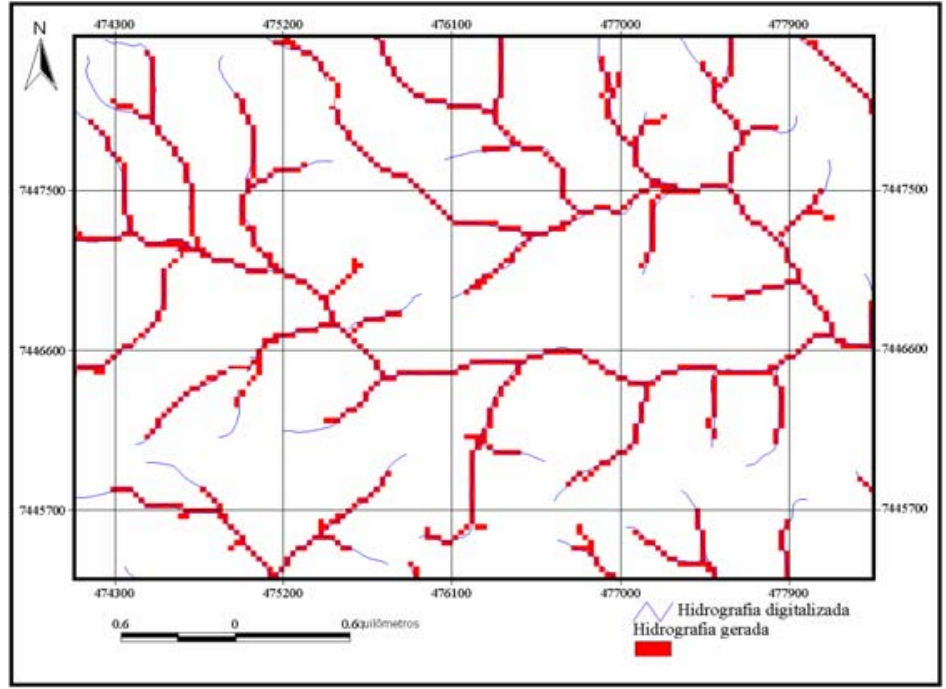

(a)

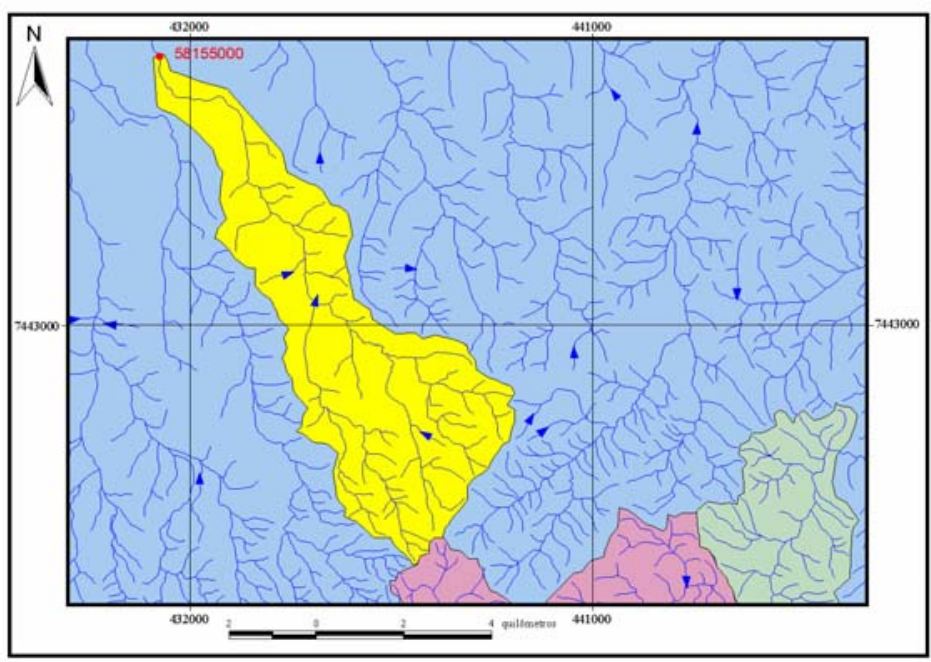

(b)

FIGURA 2. Comparação visual da rede de drenagem gerada pelo modelo com a drenagem mapeada (a); e análise da qualidade da delimitação automática das bacias de drenagem (b).

Conforme já mencionado, a definição das regiões hidrologicamente homogêneas para as vazões estudadas foi feita com base em dois critérios estatísticos: distribuição de frequiência em papel probabilístico das vazões adimensionalizadas de cada estação (critério 1) e ajuste de modelos de regressão múltipla das vazões com as características físicas e climáticas das áreas de drenagem de cada uma das estações fluviométricas (critério 2).

Inicialmente, fez-se uma tentativa preliminar de reunir todas as estações em uma só região; entretanto, todos os modelos de regressão resultantes da aplicação da regressão múltipla aos dados das 30 estações fluviométricas apresentaram coeficientes de determinação ajustados $\left(R^{2} a\right)$ insatisfatórios, com valores inferiores a 0,7 . A bacia foi dividida em mais regiões, baseando-se na distribuição geográfica das estações, na homogeneidade das características de relevo e climáticas, nos coeficientes de determinação das equações obtidas para cada região e na dispersão dos valores observados em relação aos estimados pelos modelos de regressão selecionados para cada região homogênea. 


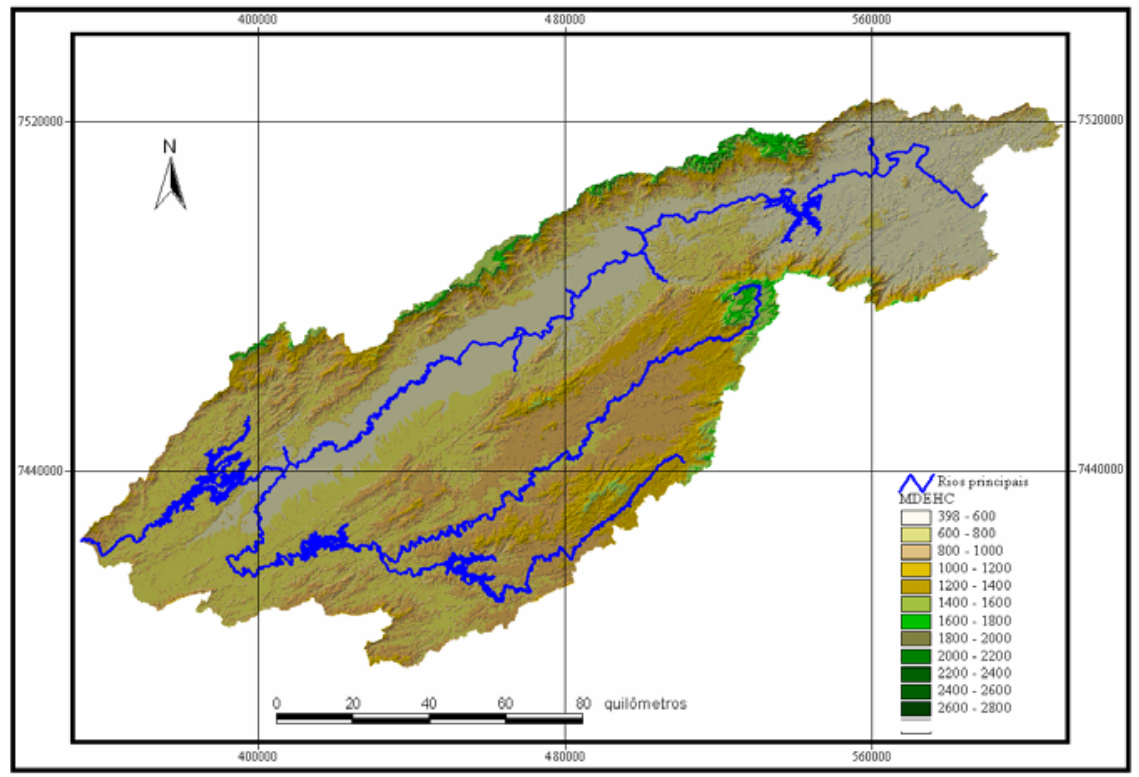

FIGURA 3. Modelo digital de elevação hidrologicamente consistente para a área em estudo.

Após diversas tentativas, identificaram-se quatro regiões hidrologicamente homogêneas para as vazões máxima, mínima e média de longo período para a bacia do Rio Paraíba do Sul, a montante da cidade de Volta Redonda (Figura 4).

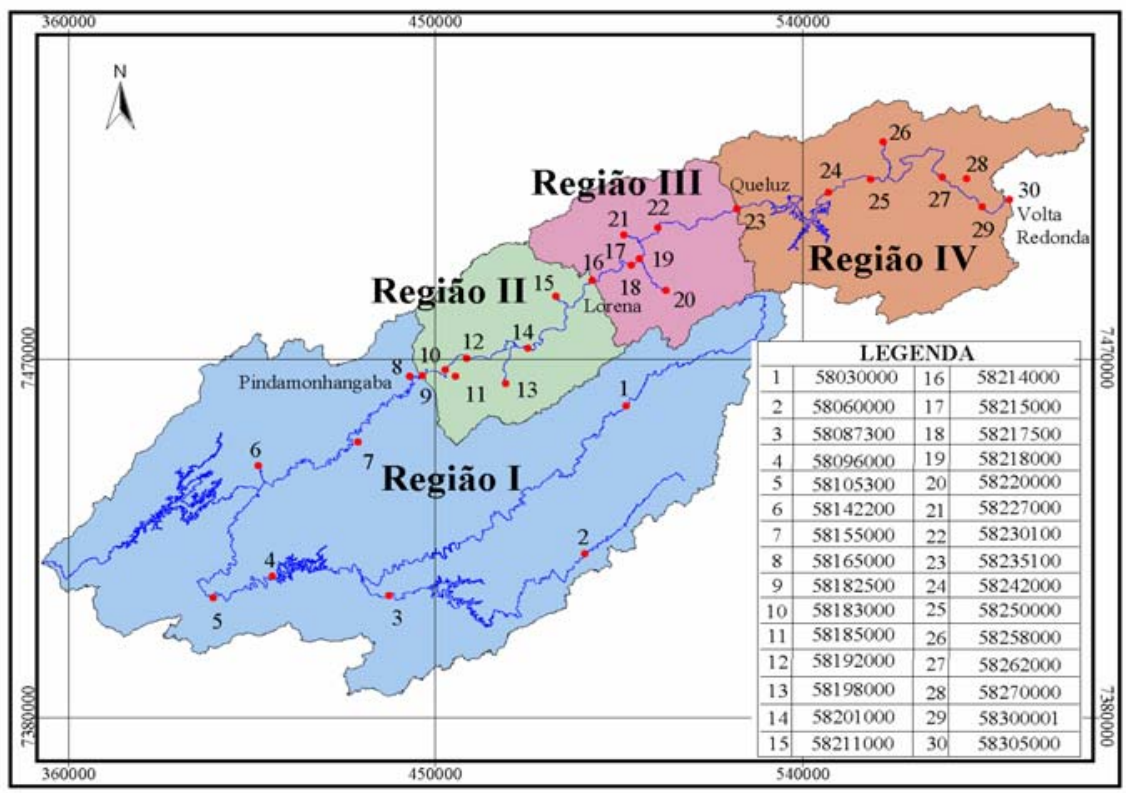

FIGURA 4. Delimitação das regiões hidrologicamente homogêneas para vazões máxima, mínima e média de longo período para a bacia do Paraíba do Sul, a montante de Volta Redonda.

A área das quatro regiões homogêneas totaliza $15.839,24 \mathrm{~km}^{2}$ e a região I se destaca pelo tamanho da área abrangida. O ideal seria uma subdivisão dessa região em duas ou mais regiões; entretanto, isso não foi possível devido à distribuição geográfica das estações, pois a região dos Rios Paraitinga e Paraibuna, formadores do Paraíba do Sul, apresenta deficiência de estações fluviométricas. Caso essa região fosse dividida, a quantidade de estações em cada região seria muito pequena, o que impossibilitaria o ajuste das equações de regressão múltipla. 
$\mathrm{Na}$ implementação do critério 2 de identificação das regiões hidrologicamente homogêneas, foram testados diversos modelos de regressão (linear, potencial, exponencial, logarítmico e recíproco), utilizando-se de várias combinações de variáveis explicativas (características físicas e climáticas), sendo que as equações recomendadas para estimar a vazão média de longo período, para as quatro regiões homogêneas, são apresentadas na Tabela 1.

TABELA1. Modelos de regressão recomendados para a representação da vazão média de longo período $\left(\overline{\mathrm{Q}}, \mathrm{m}^{3} \mathrm{~s}^{-1}\right)$ e parâmetros estatísticos a eles associados.

\begin{tabular}{cccccc}
\hline Região & Modelos Recomendados & $\mathrm{R}^{2}$ & $\mathrm{R}^{2} \mathrm{a}$ & $\sigma \mathrm{F}$ & $\mathrm{F}(\%)$ \\
\hline I & $\bar{Q}_{\text {med I }}=0,000002 \mathrm{~A}^{1,999030} \mathrm{~L}^{-1,45480} \mathrm{P}_{\mathrm{aH}}^{1,244370}$ & 0,99 & 0,99 & 1,07 & 0,000 \\
II & $\bar{Q}_{\text {med }_{I I}}=1,03 \times 10^{-11} \mathrm{~A}^{1,013383} P_{a H}^{2,902286}$ & 0,99 & 0,99 & 1,04 & 0,000 \\
III & $\bar{Q}_{\text {med III }}=0,018193 \mathrm{~A}^{1,595666} \mathrm{~L}^{-0,86242}$ & 0,99 & 0,99 & 1,14 & 0,000 \\
IV & $\bar{Q}_{\text {med IV }}=0,068763 \mathrm{~A}^{0,861867}$ & 0,99 & 0,99 & 1,11 & 0,000 \\
\hline
\end{tabular}

Analisando-se os modelos recomendados, verifica-se que a área de drenagem foi a variável que melhor explicou o comportamento das vazões médias de longo período para todas as regiões homogêneas. Nas regiões I, II e III, além da área de drenagem, os modelos de regressão recomendados contemplaram o comprimento do curso d'água principal (regiões I e III) e a precipitação total anual obtida com base no ano hidrológico (regiões I e II).

A distribuição Log-Normal com dois parâmetros foi a única que apresentou significância, a 20\% de probabilidade, pelo teste de aderência de Kolmogorov-Smirnov para todas as estações da região I, sendo, portanto, selecionada para a representação das séries de vazão máxima das estações dessa região. Para as demais regiões homogêneas, todas as distribuições testadas, à exceção da Log-Pearson III, apresentaram significância, a $20 \%$ de probabilidade, pelo teste de aderência de KolmogorovSmirnov e, por isso, a seleção foi baseada no menor coeficiente de variação. Foi adotada a distribuição Pearson III para a representação das séries de vazão máxima para as regiões homogêneas II, III e IV, por esta ter apresentado os valores mais baixos de coeficiente de variação para a maioria das estações de cada região.

$\mathrm{Na}$ Tabela 2, estão apresentados, para os distintos períodos de retorno, os modelos de regressão recomendados para estimar a vazão específica máxima $\left(\mathrm{q}_{\text {máx }}, \mathrm{m}^{3} \mathrm{~s}^{-1} \mathrm{~km}^{-2}\right)$ em cada região homogênea.

Analisando-se os resultados apresentados na Tabela 2, evidencia-se que, para a região I, se obteve boa representação da vazão específica máxima, para todos os períodos de retorno estudados, a partir de modelos recíprocos que contemplam apenas a área de drenagem e o comprimento do rio principal. Nas regiões II e III, observa-se que a área de drenagem se caracterizou como a variável mais expressiva para a representação da vazão específica máxima, para todos os períodos de retorno estudados. Para a região IV, o modelo logarítmico, contemplando apenas a declividade média da bacia, representou adequadamente a vazão específica máxima para todos os períodos de retorno analisados.

A distribuição probabilística que melhor se ajustou aos dados de vazão mínima foi a Log-Normal a três parâmetros para as quatro regiões homogêneas da bacia em estudo, visto que apresentou significância, a 20\% de probabilidade, pelo teste de aderência de Kolmogorov-Smirnov para todas as estações, além de ter apresentado valores baixos de coeficiente de variação. 
TABELA 2. Modelos de regressão recomendados para a representação da vazão específica máxima $\left(\mathrm{q}_{\mathrm{máx}}, \mathrm{m}^{3} \mathrm{~s}^{-1} \mathrm{~km}^{-2}\right)$ para diferentes períodos de retorno $(\mathrm{T})$ e parâmetros estatísticos a eles associados.

\begin{tabular}{|c|c|c|c|c|c|}
\hline $\mathrm{T}$ & Modelos Recomendados & $\mathrm{R}^{2}$ & $\mathrm{R}^{2} \mathrm{a}$ & $\sigma F$ & $\mathrm{~F}(\%)$ \\
\hline \multicolumn{6}{|c|}{ Região I } \\
\hline 2 & $q_{\max }=(4,721110-0,00504 \mathrm{~A}+0,124125 \mathrm{~L})^{-1}$ & 0,95 & 0,93 & 0,338 & 0,049 \\
\hline 10 & $q_{\max }=(-0,00686 \mathrm{~A}+0,144939 \mathrm{~L})^{-1}$ & 0,90 & 0,88 & 0,314 & 0,035 \\
\hline 20 & $q_{\max }=(-0,00654 \mathrm{~A}+0,136694 \mathrm{~L})^{-1}$ & 0,90 & 0,88 & 0,333 & 0,035 \\
\hline 50 & $q_{\max }=(-0,00619 \mathrm{~A}+0,127998 \mathrm{~L})^{-1}$ & 0,89 & 0,88 & 0,351 & 0,039 \\
\hline 100 & $q_{\max }=(-0,00597 \mathrm{~A}+0,122522 \mathrm{~L})^{-1}$ & 0,89 & 0,87 & 0,363 & 0,042 \\
\hline \multicolumn{6}{|c|}{ Região II } \\
\hline 2 & $q_{\max }=\mathrm{e}^{(-1,81877-0,00014 \mathrm{~A})}$ & 0,96 & 0,95 & 1,17 & 0,009 \\
\hline 10 & $q_{\max }=\mathrm{e}^{(-1,42314-0,00015 \mathrm{~A})}$ & 0,98 & 0,98 & 1,114 & 0,001 \\
\hline 20 & $q_{\text {máx }}=0,482006-0,04580 \ln (\mathrm{A})$ & 0,99 & 0,99 & 0,01 & 0,000 \\
\hline 50 & $q_{\max }=1,549628 \mathrm{~A}^{-0,34637}$ & 0,99 & 0,98 & 1,118 & 0,001 \\
\hline 100 & $q_{\max }=1,821129 \mathrm{~A}^{-0,35879}$ & 0,98 & 0,98 & 1,15 & 0,002 \\
\hline \multicolumn{6}{|c|}{ Região III } \\
\hline 2 & $q_{\text {máx }}=0,215848-0,01844 \ln (\mathrm{A})$ & 0,98 & 0,98 & 0,01 & 0,002 \\
\hline 10 & $q_{\max }=0,704949 \mathrm{~A}^{-0,27363}$ & 0,96 & 0,95 & 1,19 & 0,014 \\
\hline 20 & $q_{\max }=(4,471106+0,001072 \mathrm{~A})^{-1}$ & 0,96 & 0,95 & 0,62 & 0,013 \\
\hline 50 & $q_{\max }=(4,028314+0,001014 \mathrm{~A})^{-1}$ & 0,96 & 0,95 & 0,65 & 0,014 \\
\hline 100 & $q_{\max }=(3,775717+0,000978 \mathrm{~A})^{-1}$ & 0,96 & 0,95 & 0,67 & 0,014 \\
\hline \multicolumn{6}{|c|}{ Região IV } \\
\hline 2 & $q_{\text {máx }}=0,545567+0,276622 \ln \left(\mathrm{S}_{\mathrm{m}}\right)$ & 0,99 & 0,99 & 0,010 & 0,000 \\
\hline 10 & $q_{\max }=1,037109+0,540668 \ln \left(\mathrm{S}_{\mathrm{m}}\right)$ & 0,99 & 0,99 & 0,010 & 0,000 \\
\hline 20 & $q_{\max }=1,252992+0,657303 \ln \left(\mathrm{S}_{\mathrm{m}}\right)$ & 0,99 & 0,99 & 0,013 & 0,000 \\
\hline 50 & $q_{\text {máx }}=1,543906+0,814732 \ln \left(\mathrm{S}_{\mathrm{m}}\right)$ & 0,99 & 0,99 & 0,018 & 0,000 \\
\hline 100 & $q_{\text {máx }}=1,768319+0,936308 \ln \left(\mathrm{S}_{\mathrm{m}}\right)$ & 0,99 & 0,99 & 0,021 & 0,000 \\
\hline
\end{tabular}

Na Tabela 3, estão apresentados, para os distintos períodos de retorno, os modelos de regressão recomendados para estimar a vazão específica mínima $\left(\mathrm{q}_{\text {mín }}, \mathrm{m}^{3} \mathrm{~s}^{-1} \mathrm{~km}^{-2}\right)$ em cada região.

Analisando-se os resultados apresentados na Tabela 3, evidencia-se que, para a região I, se obteve boa representação da vazão específica mínima com o uso de modelos potenciais que contemplam principalmente a área de drenagem (para todos os períodos de retorno), o comprimento do rio principal para períodos de retorno menores (2; 5 e 10 anos) e a densidade de drenagem para períodos de retorno maiores (20 e 50 anos), além da precipitação do semestre mais seco para os períodos de retorno de $2 ; 5 ; 10$ e 50 anos e do trimestre mais seco para o período de retorno de 20 anos. Para as outras três regiões homogêneas, destacaram-se as variáveis independentes área de drenagem e comprimento do curso d'água principal, como as mais expressivas na representação do 
comportamento das vazões mínimas para todos os períodos de retorno estudados, à exceção da região IV para o período de 50 anos, em que, no lugar do comprimento do rio principal, foi inserida a precipitação total anual.

TABELA 3. Modelos de regressão recomendados para a representação da vazão específica mínima $\left(\mathrm{m}^{3} \mathrm{~s}^{-1} \mathrm{~km}^{-2}\right)$ para diferentes períodos de retorno $(\mathrm{T})$ e parâmetros estatísticos a eles associados.

\begin{tabular}{|c|c|c|c|c|c|}
\hline $\mathrm{T}$ & Modelos Recomendados & $\mathrm{R}^{2}$ & $\mathrm{R}^{2} \mathrm{a}$ & $\sigma \mathrm{F}$ & $\mathrm{F}(\%)$ \\
\hline \multicolumn{6}{|c|}{ Região I } \\
\hline 2 & $q_{\text {min }}=8,83 \times 10^{-8} \mathrm{~A}^{1,986850} \mathrm{~L}^{-2,61693} \mathrm{P}_{s s}^{1,745420}$ & 0,99 & 0,99 & 1,08 & 0,00 \\
\hline 5 & $q_{\min }=1,32 \times 10^{-9} \mathrm{~A}^{2,245086} \mathrm{~L}^{-2,85834} \mathrm{P}_{s s}^{2,318207}$ & 0,98 & 0,97 & 1,19 & 0,04 \\
\hline 10 & $q_{m i n}=5,84 \times 10^{-11} \mathrm{~A}^{2,424025} \mathrm{~L}^{-3,02973} \mathrm{P}_{s s}^{2,757435}$ & 0,97 & 0,95 & 1,33 & 0,17 \\
\hline 20 & $q_{\min }=-0,02773+6,91 \times 10^{-7} \mathrm{~A}+0,007805 \mathrm{Dd}+0,000115 \mathrm{P}_{\mathrm{ts}}$ & 0,97 & 0,96 & 0,00 & 0,11 \\
\hline 50 & $q_{\min }=3,18 \times 10^{-21} \mathrm{~A}^{0,600871} \mathrm{D} d^{7,932528} \mathrm{P}_{s s}^{5,104372}$ & 0,99 & 0,98 & 1,34 & 0,03 \\
\hline \multicolumn{6}{|c|}{ Região II } \\
\hline 2 & $q_{\text {min }}=0,006078 \ln (\mathrm{A})-0,00722 \ln (\mathrm{L})$ & 0,85 & 0,83 & 0,00 & 0,30 \\
\hline 5 & $q_{\text {min }}=0,008174 \ln (\mathrm{A})-0,01043 \ln (\mathrm{L})$ & 0,90 & 0,88 & 0,00 & 0,10 \\
\hline 10 & $q_{\text {min }}=0,009068 \ln (\mathrm{A})-0,01181 \ln (\mathrm{L})$ & 0,93 & 0,91 & 0,00 & 0,04 \\
\hline 20 & $q_{\min }=-0,00119+0,00969 \ln (\mathrm{A})-0,01258 \ln (\mathrm{L})$ & 0,96 & 0,94 & 0,00 & 0,17 \\
\hline 50 & $q_{\text {min }}=0,009373 \ln (\mathrm{A})-0,01245 \ln (\mathrm{L})$ & 0,93 & 0,91 & 0,00 & 0,05 \\
\hline \multicolumn{6}{|c|}{ Região III } \\
\hline 2 & $q_{\min }=0,003327+0,004630 \ln (\mathrm{A})-0,00564 \ln (\mathrm{L})$ & 0,93 & 0,89 & 0,00 & 0,48 \\
\hline 5 & $q_{\text {min }}=0,002707 \ln (\mathrm{A})-0,00249 \ln (\mathrm{L})$ & 0,85 & 0,82 & 0,00 & 0,28 \\
\hline 10 & $q_{\min }=0,002408 \ln (\mathrm{A})-0,00216 \ln (\mathrm{L})$ & 0,84 & 0,81 & 0,00 & 0,32 \\
\hline 20 & $q_{\min }=0,002203 \ln (\mathrm{A})-0,00194 \ln (\mathrm{L})$ & 0,85 & 0,82 & 0,00 & 0,56 \\
\hline 50 & $q_{\text {min }}=0,002889 \mathrm{~A}^{0,807827} \mathrm{~L}^{-1,02618}$ & 0,89 & 0,84 & 1,20 & 1,14 \\
\hline \multicolumn{6}{|c|}{ Região IV } \\
\hline 2 & $q_{\min }=0,011640+0,0000020 \mathrm{~A}-0,00003 \mathrm{~L}$ & 0,93 & 0,90 & 0,00 & 0,44 \\
\hline 5 & $q_{\min }=\mathrm{e}^{(-4,64822+0,000196 \mathrm{~A}-0,00308 \mathrm{~L})}$ & 0,92 & 0,88 & 1,06 & 0,62 \\
\hline 10 & $q_{\text {min }}=\mathrm{e}^{(-4,73519+0,000221 \mathrm{~A}-0,00344 \mathrm{~L})}$ & 0,90 & 0,86 & 1,08 & 0,92 \\
\hline 20 & $q_{\text {min }}=\mathrm{e}^{(-4,80255+0,000242 \mathrm{~A}-0,00377 \mathrm{~L})}$ & 0,89 & 0,83 & 1,10 & 1,32 \\
\hline 50 & $q_{\text {min }}=\left(293,0878-0,00625 \text { A }-0,07481 \mathrm{P}_{\mathrm{aC}}\right)^{-1}$ & 0,91 & 0,87 & 0,09 & 0,73 \\
\hline
\end{tabular}

Na Tabela 4, estão apresentados os modelos de regressão recomendados para a representação das vazões correspondentes aos níveis de permanência de 50;75; 80; 90 e 95\% em cada região. Analisando-se os resultados apresentados, evidencia-se que o melhor modelo, para todos os níveis de permanência, foi o potencial utilizando área e densidade de drenagem, sendo que, na região homogênea IV, somente a área de drenagem foi suficiente para a explicação do comportamento das vazões correspondentes aos diferentes níveis de permanência. 
TABELA 4. Modelos de regressão recomendados para a representação das vazões correspondentes a diferentes níveis de permanência $\left(\mathrm{m}^{3} \mathrm{~s}^{-1}\right)$ e parâmetros estatísticos a eles associados.

\begin{tabular}{|c|c|c|c|c|c|}
\hline $\begin{array}{c}\text { Nível de } \\
\text { Permanência }\end{array}$ & Modelos Recomendados & $\mathrm{R}^{2}$ & $\mathrm{R}^{2} \mathrm{a}$ & $\sigma \mathrm{F}$ & $\mathrm{F}(\%)$ \\
\hline \multicolumn{6}{|c|}{ Região I } \\
\hline 50 & $Q_{50}=0,0000020 \mathrm{~A}^{1,093128} D d^{9,066141}$ & 0,98 & 0,97 & 1,49 & 0,00 \\
\hline 75 & $Q_{75}=0,0000010 \mathrm{~A}^{1,134366} D d^{8,852770}$ & 0,97 & 0,96 & 1,67 & 0,01 \\
\hline 80 & $Q_{80}=9,48 \times 10^{-7} \mathrm{~A}^{1,147592} D d^{8,989948}$ & 0,97 & 0,96 & 1,68 & 0,01 \\
\hline 90 & $Q_{90}=6,04 \times 10^{-7} \mathrm{~A}^{1,198713} D d^{8,896335}$ & 0,96 & 0,95 & 1,79 & 0,02 \\
\hline 95 & $Q_{95}=3,58 \times 10^{-7} \mathrm{~A}^{1,233528} D d^{9,087540}$ & 0,96 & 0,95 & 1,87 & 0,03 \\
\hline \multicolumn{6}{|c|}{ Região II } \\
\hline 50 & $Q_{50}=0,000708 \mathrm{~A}^{1,100905} D d^{2,472620}$ & 0,99 & 0,99 & 1,07 & 0,00 \\
\hline 75 & $Q_{75}=0,000322 \mathrm{~A}^{1,150579} D d^{2,628800}$ & 0,99 & 0,99 & 1,14 & 0,00 \\
\hline 80 & $Q_{80}=0,000263 \mathrm{~A}^{1,160548} D d^{2,691190}$ & 0,99 & 0,99 & 1,18 & 0,00 \\
\hline 90 & $Q_{90}=0,000173 \mathrm{~A}^{1,183859} D d^{2,769613}$ & 0,99 & 0,99 & 1,26 & 0,00 \\
\hline 95 & $Q_{95}=0,000127 \mathrm{~A}^{1,203683} D d^{2,807423}$ & 0,99 & 0,99 & 1,34 & 0,00 \\
\hline \multicolumn{6}{|c|}{ Região III } \\
\hline 50 & $Q_{50}=0,000851 \mathrm{~A}^{1,142582} D d^{1,841232}$ & 0,99 & 0,99 & 1,20 & 0,00 \\
\hline 75 & $Q_{75}=0,000493 \mathrm{~A}^{1,183873} D d^{1,826126}$ & 0,99 & 0,99 & 1,21 & 0,00 \\
\hline 80 & $Q_{80}=0,000409 \mathrm{~A}^{1,193944} D d^{1,880986}$ & 0,99 & 0,99 & 1,21 & 0,00 \\
\hline 90 & $Q_{90}=0,000396 \mathrm{~A}^{1,201079} D d^{1,712265}$ & 0,99 & 0,99 & 1,23 & 0,00 \\
\hline 95 & $Q_{95}=0,000365 \mathrm{~A}^{1,210197} D d^{1,602552}$ & 0,99 & 0,99 & 1,27 & 0,00 \\
\hline \multicolumn{6}{|c|}{ Região IV } \\
\hline 50 & $Q_{50}=0,042957 \mathrm{~A}^{0,896561}$ & 0,99 & 0,99 & 1,09 & 0,00 \\
\hline 75 & $Q_{75}=0,020318 \mathrm{~A}^{0,964548}$ & 0,99 & 0,99 & 1,08 & 0,00 \\
\hline 80 & $Q_{80}=0,017508 \mathrm{~A}^{0,977463}$ & 0,99 & 0,99 & 1,08 & 0,00 \\
\hline 90 & $Q_{90}=0,012484 \mathrm{~A}^{1,006339}$ & 0,99 & 0,99 & 1,08 & 0,00 \\
\hline 95 & $Q_{95}=0,009124 \mathrm{~A}^{1,033302}$ & 0,99 & 0,99 & 1,10 & 0,00 \\
\hline
\end{tabular}

\section{CONCLUSÕES}

O modelo digital de elevação obtido mostrou-se hidrologicamente consistente, possibilitando a determinação automática das características físicas da bacia.

Existem quatro regiões hidrologicamente homogêneas na bacia do Rio Paraíba do Sul, a montante de Volta Redonda.

As distribuições Log-Normal com dois parâmetros (região homogênea I) e Pearson III (demais regiões) foram as que melhor representaram as séries de vazões máximas. mínimas.

A distribuição Log-Normal com três parâmetros foi a que melhor representou as séries de vazões

A área de drenagem e o comprimento do curso d'água principal caracterizaram-se como as variáveis mais expressivas para a representação das diversas variáveis e funções regionalizadas, à 
exceção da regionalização da curva de permanência, na qual a densidade de drenagem substituiu o comprimento do rio principal.

\section{REFERÊNCIAS}

BAENA, L.G.N. Regionalização de vazões para a bacia do rio Paraíba do Sul, a montante de Volta Redonda, a partir de modelo digital de elevação hidrologicamente consistente. $2002.135 \mathrm{f}$.

Dissertação (Mestrado em Recursos Hídricos e Ambientais) - Universidade Federal de Viçosa, Viçosa - MG, 2002.

CHAVES, M.A. Modelos digitais de elevação hidrologicamente consistentes para a bacia Amazônica. 2002. 111 f. Dissertação (Mestrado em Manejo Florestal) - Universidade Federal de Viçosa, Viçosa MG, 2002.

ELETROBRÁS. Centrais Elétricas Brasileiras S.A. Metodologia para regionalização de vazões. Rio de Janeiro. 1985. $2 \mathrm{v}$.

ENVIRONMENTAL SYSTEMS RESEARCH INSTITUTE. ARC/INFO v.7.1.1. Help on Line. Redlands, Califórnia: ESRI, 1997. 423 p.

EUCLYDES, H.P.; FERREIRA, P.A. Regionalização de vazões para a bacia do Alto e Médio São

Francisco. In: . Tecnologia para elaboração de projetos hidroagrícolas em bacias. Viçosa: UFV/Ruralminas, 2002. p.1-142.

FILL, H.H. Informações hidrológicas. In: BARTH, F.T.; POMPEU, C.T.; FILL, H.D.; TUCCI, C.E.M.; KELMAN, J.; BRAGA JÚNIOR, B.P.F. Modelos para gerenciamento de recursos hídricos. São Paulo: Nobel/ABRH, 1987. p. 95-210 (Coleção ABRH).

SILVA, D.D.; PRUSKI, F.F.; BAENA, L.G.N.; TEIXEIRA, A.F.; AMORIM, R.S.S. Regionalização de vazões para a Sub-Bacia 51. Brasília: ANEEL; Viçosa: UFV, 2002a. 207 p.

TUCCI, C.E.M. Regionalização de vazões. In: TUCCI, C.E.M. (Org). Hidrologia: ciência e aplicação. Porto Alegre: ABRH, 1997. p.573-619. 